\title{
ELABORAÇÃO E AVALIAÇÃO CENTESIMAL DE BARRAS DE FRUTAS DESIDRATADAS COM ADIÇÃO DE CASCAS
}

\author{
M. M. de BRITO ${ }^{1}$, A. L. O. SOUSA ${ }^{1}$, R. S. V. LIMA ${ }^{1}$, L. S. L. LIMA², V. L. de FARIAS ${ }^{2}$, M. C. F. \\ BARBOSA $^{2}$ \\ ${ }^{1}$ Instituto Federal de Educação, Ciência e Tecnologia do Ceará - Bacharelado em Nutrição \\ ${ }^{2}$ Instituto Federal de Educação, Ciência e Tecnologia do Ceará - Tecnologia em Alimentos \\ e-mail para contato: virna@ifce.edu.br
}

RESUMO - O presente estudo objetivou a elaboração de barra natural de frutas a partir do processo de secagem e posterior avaliação da sua composição centesimal. Avaliaram-se o branqueamento, os parâmetros de secagem das frutas, a obtenção das farinhas das cascas e o cálculo do rendimento, estimando as quantidades dos ingredientes do produto. A barra elaborada foi submetida à análise centesimal. O tempo ideal de secagem das polpas não branqueadas foi de 6 e 8 horas, com atividade de água de 0,401 e 0,528, e umidade de 17,33\% e $13,25 \%$ para banana e manga, respectivamente. A barra foi formulada utilizando proporção igual das polpas, e os demais ingredientes, adicionados com relação à quantidade total de polpa: $20 \%$ de pectina, $20 \%$ de farinha das cascas de manga e banana. O valor calórico por porção $(40 \mathrm{~g})$ foi de $72,27 \mathrm{kcal}$. A secagem viabilizou o máximo de aproveitamento das frutas, possibilitando a formulação de um produto natural, com baixo teor de lipídeos. Entretanto necessita-se reduzir a umidade, para melhorar sua vida de prateleira.

\section{INTRODUÇÃO}

A manga é uma fruta tropical e subtropical, com vasta possibilidade de aproveitamento (Leite $e t$ al., 1998). Segundo o IBGE (2013), no ano de 2012, a produção desta no Brasil foi de cerca de 1.175.735 toneladas, das quais aproximadamente $36 \%$, foi oriunda da produção nordestina.

A banana prata é uma fruta de alto porte, muito difundida no Brasil (Borges, 2009), representando uma grande área de produção em todo o país, com constante superação das projeções do agronegócio, estando prevista para o período compreendido entre 2012 e 2022 uma variação de 4,9\% para mais na colheita (Brasil, 2013).

O processo de desidratação de frutas oferece uma maior comodidade no consumo de frutas. Além de diminuir os custos relacionados ao transporte e também às perdas (Celestino, 2010), possibilita o acréscimo de farinhas de cascas, mesmo as que não costumam ser consumidas quando in natura. Aumenta deste modo a disponibilidade de fibras e nutrientes que estão naturalmente presentes em frutas, mas que são pouco consumidos, além de reduzir o desperdício de resíduos orgânicos, que segundo Magalhães (2002), representa por ano um prejuízo de U\$ 4 bilhões. 
Celestino (2010) afirma que apesar das eventuais perdas nutricionais ocorridas durante o processamento do alimento, o processo de secagem proporciona um alimento com valor nutricional concentrado, maior vida útil e transporte facilitado, através de mecanismos de baixo custo e com menor exigência tecnológica.

O presente trabalho teve por objetivo elaborar barra de fruta de manga e banana, utilizando o processo de secagem, com o total aproveitamento das cascas, verificando-se o rendimento e a sua composição centesimal.

\section{MATERIAIS E MÉTODOS}

\subsection{Matéria-Prima}

As frutas, sendo a manga da variedade Tommy Atkins e a banana da variedade prata, foram adquiridas no comércio local de Limoeiro do Norte (CE) em estádio de maturação considerado "de vez" (casca com partes ainda verdes na manga; e amarela com poucos pontos pretos na banana).

\subsection{Pré-Preparo}

As frutas e utensílios a serem utilizados foram higienizados por imersão em solução clorada com concentração de 100 ppm por quinze minutos, seguindo-se o enxágue em água corrente. As cascas das frutas foram retiradas e reservadas. As bananas foram cortadas em forma de disco, respeitando a circunferência natural da fruta, e com espessura de aproximadamente $4 \mathrm{~mm}$. As mangas foram cortadas em cubos de aproximadamente $4 \mathrm{~mm}$.

Parte das frutas foi branqueada antes da secagem. Neste caso, o branqueamento foi realizado por imersão das frutas, já descascadas e cortadas, em água quente, a $90^{\circ} \mathrm{C}$ por 5 minutos.

\subsection{Secagem dos Ingredientes}

As frutas foram desidratadas em estufa com circulação de ar a $70^{\circ} \mathrm{C}$ por 8 horas para a banana, e por 12 horas para a manga, devido à maior dificuldade de remoção da umidade na última. Em intervalos de duas horas, foram retiradas amostras para análise de atividade de água (Aw) e umidade, segundo IAL (2008).

Para obtenção das farinhas das cascas, estas foram submetidas ao mesmo processo de secagem, entretanto, por vinte e quatro horas ininterruptas.

A partir dos valores obtidos de umidade e atividade de água das frutas ao longo da desidratação, foram elaboradas curvas de secagem. Através destas, e por meio de observações visuais, foram estabelecidos o tempo ideal de secagem e o melhor tratamento (com branqueamento ou sem branqueamento). 


\subsection{Cálculo do Rendimento dos Ingredientes}

O cálculo do rendimento de farinhas de cascas e das polpas desidratadas foi realizado a fim de saber a quantidade destas obtida a partir de cada fruta inteira, para então elaborar as possíveis formulações da barra. Essa etapa foi realizada apenas com as frutas não branqueadas. Pesaram-se as frutas in natura, as suas polpas, as cascas, as frutas desidratadas e as farinhas das cascas.

\subsection{Formulação das Barras}

Uma vez obtidas as frutas desidratadas e a farinha das cascas, procedeu-se a elaboração das barras por método de tentativa e erro, visando definir as proporções ideais de cada componente do produto final, assim como estabelecer a quantidade de pectina a ser utilizada para a obtenção de um produto firme. Observaram-se nesse processo as características sensoriais, dando maior atenção à textura, à aparência e ao sabor. As barras foram produzidas conforme mostra a Figura 1. Os testes de formulação realizados estão expressos na Tabela 1.

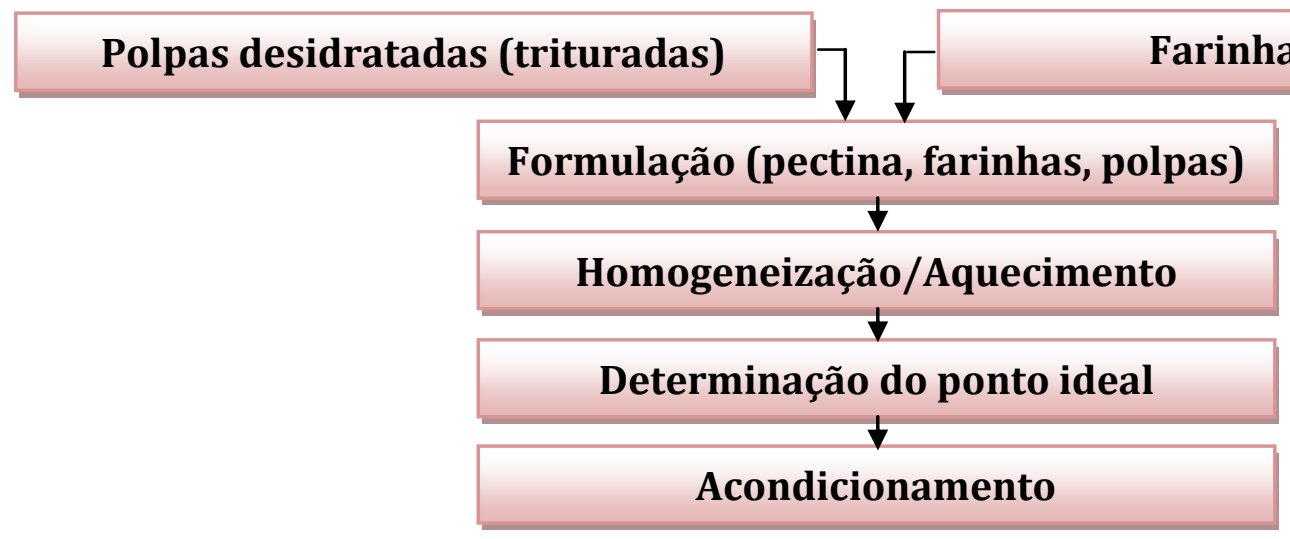

Figura 1 - Fluxograma para a obtenção da barra de frutas.

Tabela 1 - Formulações testadas para obtenção da barra de frutas

\begin{tabular}{lccc}
\hline \multirow{2}{*}{ Ingredientes } & \multicolumn{3}{c}{ Quantidade (\%) } \\
\cline { 2 - 4 } & Formulação A & Formulação B & Formulação C \\
\hline Banana desidratada & 30,0 & 32,6 & 35,7 \\
Manga desidratada & 30,0 & 32,6 & 35,7 \\
Farinha de casca de banana & 10,0 & 10,9 & 4,8 \\
Farinha de casca de manga & 10,0 & 10,9 & 9,5 \\
Pectina & 20,0 & 13,0 & 14,3 \\
\hline
\end{tabular}

\subsection{Composição Centesimal das Barras}

As barras foram analisadas quanto ao seu conteúdo de umidade (metodologia 012/IV), proteína 
bruta (metodologia 036/IV), lipídeos (metodologia 032/IV) e cinzas (metodologia 018/IV) seguindo as metodologias descritas no Instituto Adolfo Lutz (IAL, 2008). A determinação de fibra bruta se deu utilizando um analisador de fibras conforme a AOCS (2005). Os carboidratos foram determinados pela diferença entre $100 \mathrm{~g}$ do alimento e a soma dos valores encontrados em análise para os demais componentes (água, proteína, lipídeos, cinzas e fibras). Portanto foram considerados "carboidratos disponíveis". Todos os experimentos foram realizados em triplicata.

\subsection{Cálculo do Valor Calórico}

O valor calórico por $100 \mathrm{~g}$ do alimento foi determinado multiplicando-se as quantidades encontradas de carboidratos disponíveis, proteínas e lipídeos por 4, 4 e 9, respectivamente, e ao final somou-se o resultado das três multiplicações. Valor calórico $(\mathrm{Kcal})=[(\mathrm{HC} * 4)+(\mathrm{PTN} * 4)+(\mathrm{LIP} *$ 9)] (Brasil, 2003).

O tamanho da porção foi estimado tendo como referência o Guia Alimentar 0 objetivo desse trabalho foi a elaborar barras de frutas, manga e banana, utilizando o processo de secagem, com o total aproveitamento das cascas, verificando-se o rendimento e a composição centesimal para a População Brasileira (Brasil, 2005) que determina que para o grupo das frutas, deve-se considerar uma porção em gramas que forneça valores aproximados de $70 \mathrm{kcal}$. Tendo como base esta informação, após os cálculos de valor energético considerando os componentes determinados em análise centesimal, calculou-se o valor energético considerando uma porção de $40 \mathrm{~g}$ do produto, que fornece valores aproximados com o recomendado para o grupo das frutas.

\section{RESULTADOS E DISCUSSÕES}

\subsection{Curvas de Secagem}

O teor de umidade e a atividade de água das bananas branqueadas e não branqueadas durante a secagem variaram conforme mostra a Figura 2. O comportamento desses parâmetros para as mangas está ilustrado na Figura 3.

Os resultados condizem com o encontrado por Borges et al.. (2010), em estudo sobre as diferentes formas de secagem de banana prata. As frutas em forma de discos desidratadas a $70^{\circ} \mathrm{C}$ apresentaram comportamento semelhante aos gráficos do presente estudo. Os autores afirmaram que a $70^{\circ} \mathrm{C}$ o processo de branqueamento não possui efeito acentuado, pois este aumenta a permeabilidade do alimento ao calor, entretanto gelatiniza o amido presente na fruta, o que a reduz e, portanto, compensa o efeito. 

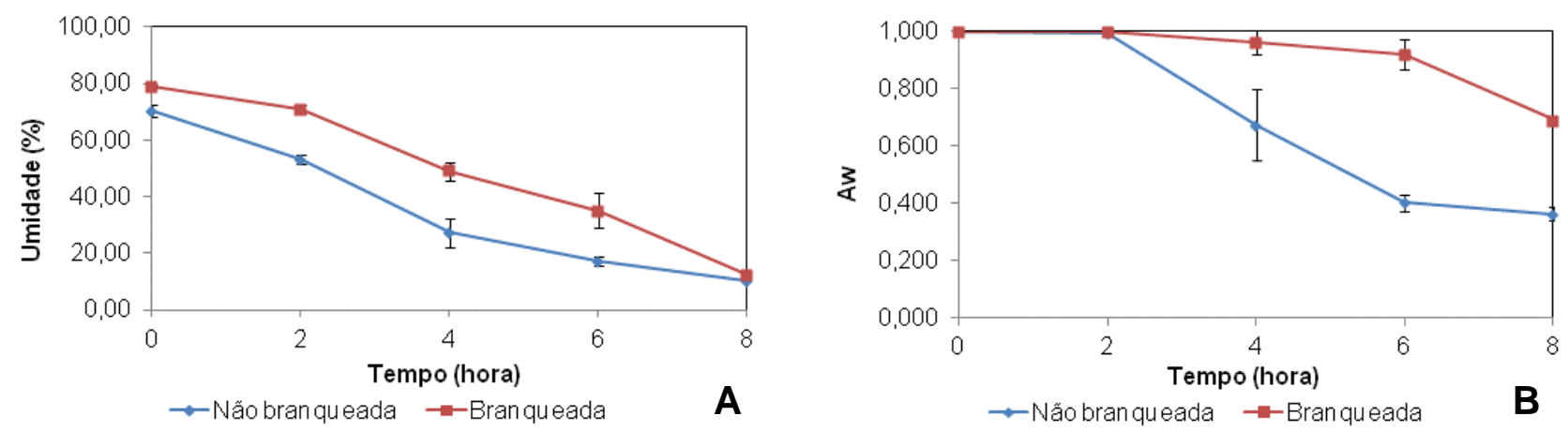

Figura 2 - Desidratação de bananas não branqueadas e branqueadas. A - Variação da umidade, B - Variação da atividade de água (Aw).
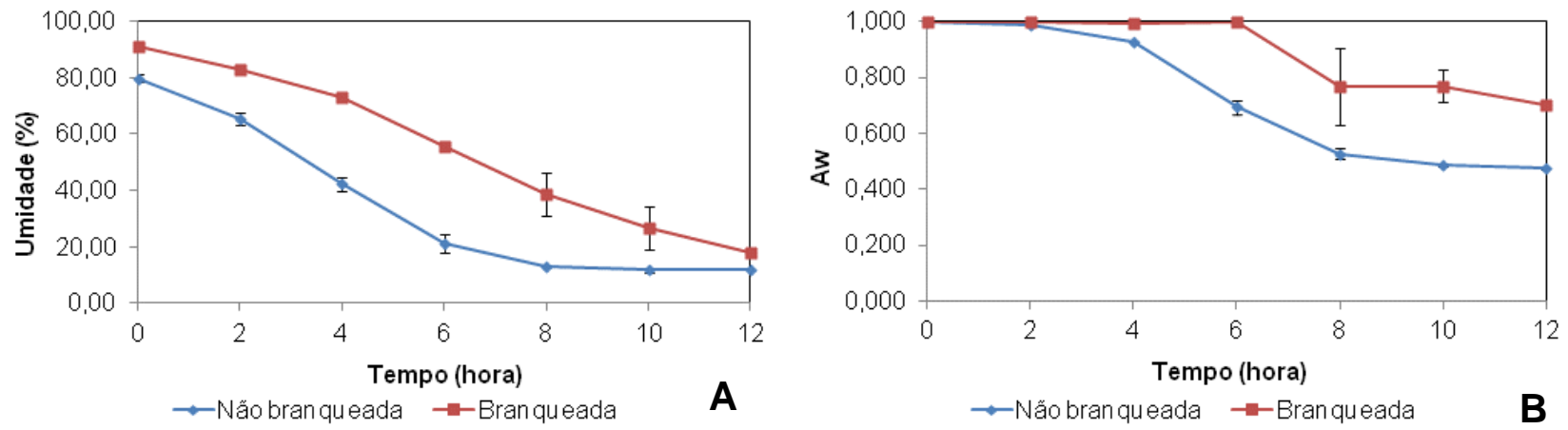

Figura 3 - Desidratação de mangas não branqueadas e branqueadas. A - variação da umidade, B - Variação da atividade de água (Aw).

De acordo com os valores de umidade e atividade de água obtidos, e através de observação visual, foram selecionados os tempos ideais de secagem, de modo que as frutas desidratadas apresentassem menor umidade e ao mesmo tempo obtivessem características sensoriais agradáveis e condizentes com a ideia do produto final. Desta forma, o melhor tempo foi de seis horas para a banana e de oito horas para a manga, sendo estas não branqueadas. Nessas condições banana e manga apresentaram atividade de água de 0,401 e 0,528 e umidade de $17,33 \%$ e 13, $25 \%$ respectivamente.

Devido à redução de umidade e atividade de água mais lenta nas frutas branqueadas, e por não ter sido observado benefícios do branqueamento nas polpas secas para o objetivo desse estudo, optouse por utilizar as frutas desidratadas não branqueadas para a formulação do produto.

Com o aumento da escala, a secagem das frutas não ocorria de maneira homogênea. Sendo assim, após o tempo de processamento estabelecido para as frutas, estas eram trituradas e recolocadas em estufa até que atingissem a atividade de água pré-estabelecida para cada uma. 


\subsection{Rendimento dos ingredientes}

Pelos resultados apresentados na Tabela 2, verificou-se que o rendimento, tanto em polpa quanto em farinha da casca, é menor para a manga. A proporção farinha de casca: fruta desidratada, para ambas as frutas, é de aproximadamente 1:3. Isso significa que para a elaboração das formulações a serem testadas foram sugeridas apenas proporções farinha: fruta desidratada que fossem possíveis se obter no processamento de cada fruta.

Tabela 2 - Rendimento em polpa desidratada e farinha da casca.

\begin{tabular}{lcc}
\hline \multirow{2}{*}{ Fruta } & \multicolumn{2}{c}{ Rendimento $(\%)$} \\
\cline { 2 - 3 } & Fruta desidratada & Farinha da casca \\
\hline Banana & 18,96 & 5,61 \\
Manga & 11,64 & 3,17 \\
\hline
\end{tabular}

\subsection{Elaboração das Barras}

Dentre as proporções testadas (Tabela 1) escolheu-se como a melhor a barra formulada seguindo a Formulação $\mathrm{C}$, por resultar em um produto mais firme e de melhor sabor, além de apresentar características físicas mais semelhantes com produtos comercializados no mercado. Nesta utilizou-se 35,7\% de cada fruta desidratada, às quais foi acrescentada uma maior quantidade de farinha da casca da manga $(9,5 \%)$ em detrimento da farinha da casca da banana $(4,8 \%)$, por esta interferir negativamente no sabor do produto final. Deste modo, o produto é composto de 71,4\% de polpa desidratada, com acréscimo de $14,3 \%$ de farinha de cascas, aderidas por $14,3 \%$ de pectina.

\subsection{Composição Centesimal das Barras}

A Tabela 3 apresenta os valores percentuais dos componentes da barra de frutas que apresentou melhor formulação.

Tabela 3 - Composição centesimal da barra de frutas.

\begin{tabular}{ll}
\hline Composição & $\mathbf{g . 1 0 0 g}^{-1}$ \\
\hline Umidade & $53,33 \pm 1,24$ \\
Proteínas & $2,40 \pm 0,25$ \\
Lipídeos & $0,16 \pm 0,08$ \\
Cinzas & $1,34 \pm 0,01$ \\
Fibras & $2,95 \pm 0,18$ \\
Carboidratos disponíveis* & 42,77 \\
\hline \multicolumn{2}{c}{$*$ Calculado por diferença dos outros componentes }
\end{tabular}

Destacou-se nesse produto seu elevado teor de umidade. Segundo a RDC No. 272, de 22 de setembro de 2005, a umidade em produtos de frutas secos ou desidratados deve ser de até $25 \%$. (Brasil, 2005). Verificou-se, portanto, que o preparo da barra de frutas deve ser melhorado nesse 
sentido, de forma a se obter um produto menos úmido, resultando em uma maior expectativa de vida útil.

\subsection{Valor Calórico}

Após análises e determinação da composição centesimal da barra de frutas adicionada farinha das cascas, foi possível estabelecer que uma porção de 40 gramas do produto possui valor energético de 72,27 kcal. A Tabela 4 expõe a informação nutricional para uma porção da barra de frutas.

\section{Tabela 4 - Rotulagem nutricional da barra de frutas.}

\begin{tabular}{|l|c|c|}
\hline \multicolumn{2}{|c|}{$\begin{array}{l}\text { INFORMAÇÃO NUTRICIONAL } \\
\text { Porção de 40g (1 unidade) }\end{array}$} \\
\hline \multicolumn{2}{|c|}{ Quantidade por porção } & $\%$ VD(*) \\
\hline Valor energético & $72,27 \mathrm{kcal}=300 \mathrm{~kJ}$ & 4 \\
\hline Carboidratos & $17,10 \mathrm{~g}$ & 6 \\
\hline Proteínas & $0,96 \mathrm{~g}$ & 1 \\
\hline Gorduras totais & $0 \mathrm{~g}$ & 0 \\
\hline Gorduras saturadas & $0 \mathrm{~g}$ & 0 \\
\hline Gorduras trans & $0 \mathrm{~g}$ & 0 \\
\hline Fibra alimentar & $1,18 \mathrm{~g}$ & 5 \\
\hline
\end{tabular}

(*) \% Valores diários de referências com base em uma dieta de 2000 kcal ou 8400 kJ. Seus valores diários podem ser maiores ou menores dependendo se suas necessidades energéticas.

\section{CONCLUSÃO}

O processo de secagem viabilizou o máximo aproveitamento das frutas, possibilitando a formulação de um produto natural. A melhor formulação consistiu de proporção igual das polpas, e os demais ingredientes, adicionados com relação à quantidade total de polpa: $20 \%$ de pectina, $20 \%$ de farinha das cascas de manga e banana. O produto final caracterizou-se pelo baixo teor de lipídeos. Entretanto necessita-se reduzir a umidade do produto, com a expectativa de melhorar sua vida de prateleira.

\section{REFERÊNCIAS}

AOCS. Official method Ba 6a- 05. Crude Fiber Analysis in Feeds by Filter Bag Technique. In: Official Methods and Recommended Practices of the AOCS. Association of Oil Chemists Society. 2005.

BORGES, S. V; MANCINI, M. C.; CORRÊA, J. L. G.; LEITE, J. Secagem de Bananas Prata e d'água por Convecção Forçada. Cie. e Tec. de Alim. Online. p. 605-612, 2010. Disponível em < http://www.scielo.br/pdf/cta/v30n3/v30n3a06>. Acesso em: 19/04/2014.

BORGES, A. L.; SILVA, A. L.; BATISTA, D. C.; MOREIRA, F. R. B.; FLORI, J. E.; OLIVEIRA, J. E. M.; ARAÚJO, J. L. P.; PINTO, J. M.; CASTRO, J. M. C.; MOURA, M. S. B.; AZOUBEL, P.; CUNHA, T. J. F.; SILVA, S. O.; CORDEIRO, Z. J. M. Sistema de Produção da 
Bananeira Irrigada. EMBRAPA Semiárido. Sist. De Prod. Julho, 2009.

BRASIL, MINISTÉRIO DA SAÚDE. Secretaria de Vigilância em Saúde. Departamento de Vigilância de Doenças e Agravos não Transmissíveis e Promoção de Saúde. Vigitel Brasil 2012: vigilância de fatores de risco e proteção para doenças crônicas por inquérito telefônicoBrasília: Ministério da Saúde, 2013

BRASIL, MINISTÉRIO DA SAÚDE. Secretaria de Atenção à Saúde. Coordenação-Geral da Política de Alimentação e Nutrição. Guia alimentar para a população brasileira: promovendo a alimentação saudável. Brasília: Ministério da Saúde, 2005.

BRASIL. Resolução n ${ }^{\circ}$ 272, de 22 de setembro de 2005. Regulamento técnico para produtos de vegetais, produtos de frutas e cogumelos comestíveis. Diário Oficial da União, Brasília, DF, 22 de dezembro de 2000.

BRASIL. Ministério da Agricultura, Pecuária e Abastecimento. Projeções do Agronegócio : Brasil 2012/2013 a 2022/2023 / Minist. da Agric.a, Pec. e Abast. Assessoria de Gestão Estratégica. Brasília: Mapa/ACS, 2013.

CELESTINO, S. M. C. Princípios de Secagem de Alimentos. EMBRAPA Cer. p. 9-35, 2010.

IAL. INSTITUTO ADOLFO LUTZ. Normas Analíticas: Métodos físico-químicos para análise de alimentos. IAL: São Paulo, 2008. 4. ed. 1020 p.

IBGE. Instituto Brasileiro de Geografia e Estatística Produção Agrícola Municipal: Culturas Temporárias e Permanentes. IBGE. Prod. agric. munic., Rio de Janeiro, v. 39, p.1-101, 2012.

LEITE, L. A. S.; PESSOA, P. F. A.; ALBUQUERQUE, J. A.; SILVA, P. C. G. Cadeias produtivas $e$ sistemas naturais: prospecção tecnológica. Brasília, DF: EMBRAPA-SPI: EMBRAPA-DPD, 1998. cap. 16, p. 389-439.

MAGAlHÃES, L. M. Lixo e Desperdício, Perspectiva numa Sociedade de Consumo. 2002. Monografia. Universidade Cândido Mendes. Rio de Janeiro, 2002.

PORCIUNCULA, B. D. A. Desenvolvimento de Processo Integrado de Desidratação e Modificação da Textura de Banana (Var. Prata) por Secagem Convectiva e Pulsos de Vácuo. Dissertação. Florianópolis, SC, 2010. 96 p.

TACO. Tabela Brasileira de Composição dos Alimentos. NEPA-UNICAMP.- 4.ed. ver. e apl.. -Campinas: NEPA- UNICAMP, 2011. 161p. 